Review

\title{
Biophobia and Urban Restorativeness
}

\author{
Agnès Patuano \\ Landscape Architecture and Spatial Planning Group, Wageningen University \& Research, P.O. Box 47, \\ 6700 AA Wageningen, The Netherlands; agnes.patuano@wur.nl
}

Received: 16 March 2020; Accepted: 15 May 2020; Published: 25 May 2020

\begin{abstract}
Natural areas are now known to be important resources for the health and wellbeing of urban dwellers, through, for example, the opportunities they provide for cognitive and emotional restoration. However, urban populations have also been found not to engage with these spaces and to display some form of biophobia which may hinder them from perceiving any of these benefits. This concept of biophobia is thought to entail both our innate physiological responses to the perceived danger from non-human threats such as spiders and snakes and our cultural attachment to material comfort. The word is often used with derogatory connotations, even if it is part of an evolutionary mechanism honed over thousands of years to keep humans alive. This review presents the current state of knowledge on urban biophobia as well as evidence of instances in which built and mixed urban environments were found to be more restorative than natural ones for the urban population, in order to assess any connection within the two. A series of recommendations for further research but also for the practical implementation of natural areas in cities capable of attracting a wide variety of people regardless of their fears or preferences are also formulated. Only by investigating the psychological and physiological responses of urban dwellers to their daily environments can we hope to design interventions which will remain relevant for the modern world.
\end{abstract}

Keywords: biophilia; built environment; restorativeness; fear

\section{Introduction}

As the benefits of engaging with nature become more well known, the evidence basis for them continue to grow [1-3]. In urban contexts, green spaces have for example been linked to improved relaxation and psychological restoration of cognitive and emotional functions, improved social capital, improved functioning of the immune system, improved fitness and reduced obesity, and to the reduction of anthropogenic noise buffering, exposure to air pollution and urban heat island effect [1].

Although these benefits have been shown to be particularly important for vulnerable or deprived populations [4], they are also broadly thought to be universal to every human being. Yet, it is clear that not everyone is so enthusiastic about nature. In fact, there is a general acknowledgement that regular interactions between people and nature have been in persistent decline $[5,6]$. However, negative perceptions of nature are rarely studied $[7,8]$. Similarly, although we live in an increasingly urbanised world, positive perceptions of built urban environments are scarcely investigated [2,9,10].

The claims of a universal psychological need for nature are linked to the theoretical basis of most of the work undertaken in the field. Indeed, the strand of environmental psychology devoted to exploring the links between natural environments and health generally operates based on evolutionary assumptions, such as the biophilia hypothesis which posits that humans have developed innate physiological and psychological responses to elements and settings which might promote survival as a result of spending much of their history embedded in a natural environment $[2,11,12]$. These assumptions are now being critically assessed for their inability to take into account the importance of culture and personal experiences. Similarly, some evidence suggest that just as humans 
adapted to the environmental conditions in which they evolved, they can also adapt to the "new" urban context in which the overwhelming majority of us now live [13].

A lifestyle is typically understood as the set of attitudes and behaviours shared by a group [14]. Using this framework, most of the Western world lives an urban lifestyle. However, this fact is rarely taken into account when discussing people's perspectives on natural processes. Generally, it seems that, although urban dwellers value the proximity of natural areas, their perceptions (i.e., what they perceive as a "natural" area or how they experience actually engaging with natural elements) and behaviours (i.e., how much they actually visit that area) are not always in line with their opinion [15].

In this paper, I attempt to explore the conditions in which built and mixed urban environments may be more restorative than natural ones and whether this new trend is the result of modern biophobia. To do so, I review the existing corpus of evidence on urban dweller's perspectives and experiences of natural environments, provided by studies carried out within the disciplines of landscape design, urban planning, and environmental psychology, and collected from a critical standpoint on the nature/urban dichotomy. The objective is to provide an overview of the current discourse on built and mixed urban environments from an environmental psychology perspective as well as formulate practical recommendations for researchers and designers looking to develop sustainable and liveable green spaces in cities for the benefit of populations both present and future.

The first part of this paper presents the health benefits of natural environments such as they are described in the literature, looking first at the theoretical basis for them then to their limitations as they pertain to biophobia. In a second section, the literature regarding the health benefits of urban built and mixed environments is presented, starting with the traditional and historical perspective on their effects on human health then moving on to explore the emerging empirical evidence of their potential benefits. Finally, the different strands of research are discussed and several recommendations are proposed for future research and practical implementations of future green spaces within the built urban framework.

\subsection{Methodology}

The objectives of this paper are twofold. First, it aims to bring together studies on the potential restorativeness of built and mixed urban environments and the empirical evidence for biophobia in urban dwellers to observe any linkage and overlap (e.g., do people who experience biophobia find urban environments more restorative than natural areas?). Secondly, it attempts to translate some of the current strands of research on these two topics into practical recommendations for the planning and design of restorative urban green spaces which can benefit a variety of individuals regardless of their pre-existing connection to nature.

This critical review aims to answer one general research question: Can built and mixed urban spaces be more restorative than natural ones for biophobic populations? In doing so, it provides elements of answers to several sub-questions such as

- Are natural environments always more restorative than built ones?

- For which populations are natural environments not restorative?

- Can built and mixed urban environments be restorative?

- For which populations are built and mixed environment restorative?

- Is this linked with a physiological or cultural biophobia?

- Is it possible to design natural areas within an urban framework which maximise restoration and minimises biophobia?

To meet these aims and objectives, a systematic literature review of peer-reviewed articles published in international scientific journals was conducted in January 2020. Google Scholar was used as the scientific search engine to find appropriate articles. The search profile was based on a number of primary search terms related to the research questions and sub-questions. The first main term related to the topic of 'biophobia', the second to 'urban restorativeness' and associated concepts such as 'preference' and 'perceived restorativeness', the third to socio-economic and socio-demographic 
profiles of specific populations, and included key search terms such as 'age' and 'deprivation' but also 'familiarity'. The respective terms were chosen based on the author's own experience with the topic and other reviews, existing theories and initial literature studies that revealed some gaps in knowledge on the restorative potential of built and mixed urban environments and its possible links with biophobia. Papers using these terms as keywords or in their abstracts were included, as long as they were coming from disciplines such as landscape design, urban planning and environmental psychology. Disciplines outwith these are also outside of the author's area of expertise and were assessed as less likely to provide claims and evidences which could be translated into design recommendations as is one of the objectives of the present review. Although the only language this review was conducted in was English, papers from diverse cultures and socio-economic contexts were included in order to assess the claim of biophobia being a universal trait. Reference sections of the selected papers were also examined for additional studies.

As the literature on the health benefits of green and natural spaces were already familiar to the author, studies specifically looking at built environments were included in priority. Studies focussing on the positive effect of natural elements in an urban context, for which strong evidence already exists, were only included if they also considered specific populations or if the environmental stimulus used to represent the "urban" side of the nature-urban dichotomy was not solely chosen for its deficiencies. This selection process is similar to the one used by Weber and Trojan [16] in their review of existing literature on the restorative value of the urban environment. Indeed, they chose not to include "studies that only addressed the restorative effects of nature, [or] comparing nature to urban settings" [16] (p. 3). However, contrary to their inclusion and exclusion process, studies investigating preferences (as opposed to solely restorativeness) for urban locations were also included here as the correlation between preference and restorativeness is well-studied (see for example $[17,18]$ and Section 2.1 on p. 6 of this review).

In total, only 10 empirical studies on the potential restorativeness of predominantly built and mixed urban environments could be found (see Table 1). Again, this mirrors the results of Weber and Trojan who found so "few studies concerned with the relationship between restoration likelihood and built urban features, [they] expanded [their] search to human-made natural elements in urban contexts" [16] (p. 2). On the specific topic of biophobia and restoration, 15 studies were found, 5 of which were reviews with no primary research results. No study could be found that specifically linked of biophobia and urban restorativeness.

All final articles were analyzed using a standardized data extraction sheet based on pre-defined questions for review. This included general information such as publication date, case-study location, respective topic or issue of interest, particular sampling methods for sites and participants and results observed.

Table 1. Studies specifically on the potential restorativeness of built and mixed urban environments reviewed (by alphabetical order).

\begin{tabular}{ccc}
\hline Authors & Topic & Location \\
\hline Fornara and Troffa [19] & Restorative potential of different urban environments & Italy \\
Hidalgo et al. [20] & Restoration and preference & Spain, Italy \\
Karmanov and Hamel [9] & Restorative potential , natural vs. urban environments & The Netherlands \\
Lindal and Hartig [21] & Restorative potential of residential areas & Iceland \\
San Juan et al. [10] & Restorative potential of urban squares & Spain \\
Scopelliti and Giuliani [22] & Restorative potential, natural vs. urban environments & Italy \\
Scopelliti et al. [22] & Restorative potential, natural vs. urban environments & Italy \\
Staats et al. [23] & Preference and restoration of urban activities-in-environments & Sweden, USA, NL \\
Stigsdotter et al. [24] & Restorative potential, natural vs. urban environments & Denmark \\
Subiza-Perez et al. [25] & Environmental characteristics and restoration & Spain \\
\hline
\end{tabular}




\subsection{Definition of Environmental Characteristics}

One of the issues faced by the author when collating the literature was the many ambiguities of the terminology used to describe different types of environments, including "green spaces" [1,26]. Similarly, it is important to point out not all studies included in this review provided many details about the type of environment they chose to focus on $[20,23]$.

In this review, 'natural environments' refer to large and medium-sized parks, forests, wild and rural areas, allotments and community gardens, or settings which are primarily natural through their elements and surfaces and contain very few man-made elements. 'Mixed environments' refer to environments which are somewhat equal in their proportions of natural and man-made elements such as pocket parks, plazas, or residential streets with front gardens and balcony greens. 'Built environments' refer to primarily man-made environments with a majority of hard surfaces and a high density of built elements, such as streets and malls.

It can be quite difficult to accurately characterise environments using a narrow and precise terminology as two people might also perceive these spaces differently. The objective here is not to provide an exhaustive categorisation of all possible environments but solely the ones used in the studies included in this review. As such, urban green spaces can straddle the delineation between natural and mixed environments and this was assessed on a study-by-study basis.

\subsection{Cultural and Geographical Perspective}

Aside from considering the geographical context as it is expressed in the characteristics of the local environment, it is also important to take into account the importance of culture when discussing human-environment relationships. Although the Western world has produced the great majority of studies on the restorative benefits of nature in the past, Asian countries have also started to significantly contribute to the discussion.

Several articles on biophobia in urban children in China and Japan included in this review support the claim for the universality of this concept, at least in developed, densely urbanized countries $[5,27,28]$. Unfortunately, the majority of studies on this topic, and on the topic of urban restorativeness remain from a Western perspective. As a result, and unless otherwise specified, this is also the perspective from which this critical review was written.

\subsection{Theoretical Background}

Before assessing the empirical evidence for the restorative potential of built and mixed environments, it is important to understand the theoretical approach behind this strand of research on human-environment relationships.

\subsubsection{Biophilia}

'Biophilia' (from the Greek bio: organic life and philia: love) is a concept first introduced in 1964 by Erich Fromm, the German psychologist and philosopher, who described it as a universal psychological attraction towards anything that is alive. The concept was then popularised by Edward O. Wilson, an American biologist, in his 1993 book The Biophilia Hypothesis , a compilation of studies edited and published with Stephen R. Kellert. It is sometimes defined as "the innately emotional affiliation of human beings to other living organisms" [29] (p. 31) or "the connections that human beings subconsciously seek with the rest of life" [30] (p. 86).

The biophilia hypothesis is based on the idea that humans have shared a close relationship with their natural environments for most of their existence on the planet. This relationship is thought to have shaped much of humanity's genetic material as environmental adaptations. Even though the last 5000 years were largely spent either controlling (through agriculture) or transforming (through urbanisation) natural environments, those genetic adaptations are thought to have survived. In modern 
society, they transformed into a universal affinity for other living things, and into a need to be in contact with nature.

Ever since its introduction, the biophilia hypothesis has been the subject of many critiques. On a theoretical level, the concepts it articulates such as the fundamental idea of connection, affiliation or resonance, are rather vague at best. Similarly, although there are plenty of evidence to support the general idea that contact with nature has a positive effect on human health, not much empirical evidence has been found to support the specific claims of biophilia for an "innate" resonance with "all" living things [2,12]. Finally, the evolutionary assumptions on which it rests have also been criticised for not clearly delimiting the importance of genetic versus cultural factors [2,13]. Regardless of its limitations, there is no denying that the concept of biophilia has been a valuable stimulus and starting point for research and discussions on human-environment relationships.

\subsubsection{Biophobia}

Parallel to this new concept, Kellert and Wilson also defined the one of 'Biophobia'. The original description of the concept comes in two of the papers included in The Biophilia Hypothesis [29].

The first one, written by Ulrich, tackles the innate genetic tendency to develop fear or strong negative avoidance responses to certain natural stimuli, settings or situations which would have presented a threat to human survival during our evolution [31]. This tendency, by increasing the likelihood of survival of our ancestors who would have regularly encountered such threats, would have then been passed on through the process of natural selection. Even further, these responses have been shown to be unconscious and somewhat "unforgettable" [31] (p. 85). The studies included in that original review all point to a genetic basis for their findings, which also supports the idea that the tendency to biophobic responses is universal.

However, in the second paper, David Orr describes biophobia as "the culturally acquired urge to affiliate with technology, human artefacts, and solely with human interests regarding the natural world" [32] (p. 187), articulating avoidance responses as based less in fear than in disgust. In other words, although both Ulrich and Orr discuss the same concept, the former considers biophobia as natural, the latter as cultural.

As opposed to biophilia, biophobia has been supported by a large corpus of empirical evidence [2]. Indeed, many behavioural studies including conditioning experiments seem to validate the claim that humans and primates have a biological tendency to acquire and to remember adaptive fear or avoidance responses to natural threats such as snakes and spiders [12].

\section{The Health Benefits of Green Spaces: Theories, Evidence and Limitations}

The health benefits of natural and wild environments are varied and far-reaching. But how do these places promote health and wellbeing? Are all settings providing the same benefits, and do all populations perceive them equally? This section presents the theoretical background for the positive effect of natural elements and environments on human health and the limitations created by biophobia.

Generally, pathways to health from natural environments are sometimes thought of as four-fold and include: physiological processes (clean air, etc.), physical processes (by offering opportunities for physical activity), social processes (by increasing the likelihood of social contact) and psychological processes (such as relaxation and restoration). Of these four pathways, the latter is most influenced by notions of biophilia or biophobia and is therefore the main focus of this review.

\subsection{Theories of Physical, Social and Psychological Restoration}

The health benefits of engaging with natural environments are sometimes grouped under the umbrella term 'restoration' $[10,11]$. This phenomenon can be defined as a renewal of diminished functional resources and capabilities [11], or more precisely "the process of renewing or recovering physical, psychological and social capacities that have become depleted in meeting ordinary adaptational demands" [33] (p. 281). 
Generally, studies interested in this concept will often use the Perceived Restorativeness Scale (PRS [34]) in order to assess a environment's restorative potential [10,17,19-21,24,25,35-37]. This scale was developed with the objective of capturing the type of restoration described by the Kaplans for ART and, as such, it is comprised of several questions, each accounting for a different aspect of restorative experiences (specifically Being Away, Fascination, Coherence, and Compatibility).

Studies interested in the restorativeness of environments might also consider preference as a proxy or confirming variable (see for example $[10,19,20,38]$ ). Indeed, there is a well-known link between preference and restoration [17,18], or perceived restoration [37], and other studies have found out that people may expect the environments they like to be restorative regardless of their actual effect [35].

The term "restoration" itself is directly borrowed from Stephen and Rachel Kaplan's Attention Restoration Theory (ART), one of the most popular theoretical framework to understand the effects of visiting green spaces on cognition and wellbeing.

\subsubsection{Attention Restoration Theory}

According to the Kaplans, humans have two distinct modes of attention: (a) the directed attention, which is what people use to process information and carry out daily tasks, like driving, working or searching for their keys; and (b) effortless attention, sometimes also called 'soft fascination', which is a less focussed type of attention where the mind is allowed to "rest and wander freely" [39]. The capacity of (a) is finite and gets rapidly depleted. After a certain time, or a certain amount of information, its quality decreases. According to ART switching one's mode from (a) to (b) allows the restoration of (a) to full capacity.

However, not all natural environments are equal in their ability to provide a restorative experience. Instead, they need to provide four key attributes:

- Extent: A scope wide enough that one can feel immersed in the environment.

- A sense of being away: The landscape needs to extend far enough that one can feel immersed in it, but it also need to provide an escape from daily life.

- Soft fascination: As described above, soft fascination is also called effortless attention, and it requires aspects of the environment that capture attention effortlessly such as wildlife. interesting elements and changes in vegetation.

- Compatibility: Individuals must want to be exposed to, and appreciate, the environment.

Using this theoretical framework, many studies have found that time spent in nature could improve recuperation from mental fatigue in the form of, for example, proofreading performance [40] or performance on standardised mental concentration tests [18]. For readers interested in a more comprehensive presentation of the attention restoration potential of exposure to natural environments, Ohly et al. [41] provide a systematic review.

Although the Kaplans were quite clear on the fact that restoration was purely affecting cognitive processes, this term is now used to encompass some of the other benefits of visiting green spaces such as relaxation and relief from stress [10].

\subsubsection{Psycho-Evolutionary Theory}

The second most popular theory to explain the effect of environments on health and well being is Roger Ulrich's Psycho-Evolutionary Theory (PET, sometimes also referred to as Stress Recovery Theory $[10,13])$. It encompasses a wide range of emotional and physiological responses to natural scenes, including stress recovery.

As opposed to the Kaplans, Ulrich postulates that our immediate and unconscious emotional responses, rather than more 'controlled' cognitive ones, can influence our attention, physiology and behaviour [42]. This theory implies that the rapid attenuation of stress responses after threatening encounters and the quick recharge of physical energy had major advantages for humans during their evolution. Consequently, modern humans are thought to exhibit an innate restorative response to the natural settings they perceive as safe [42]. 
For this perception of safety, Ulrich [43] posits the need for certain elements including the presence of water and vegetation. Similarly, he relates stress to an increase in negative emotion and in arousal [2,42] which also implies that "recuperation from excessive arousal or stress should occur more rapidly in settings having low levels of arousal increasing properties such as complexity, intensity and movement" [42] (p. 205).

Evidence for the emotional and psychological benefits of engaging with natural environments such as described in PET include the observable decrease in skin conductance and muscle tension [42], better self-reported moods [40] and a link between green space provision and self-reported stress and salivary cortisol patterns in deprived communities [44].

\subsubsection{Prospect-Refuge Theory}

Another theory, the prospect-refuge model, is particularly relevant here. Also based on evolutionary assumptions, it formulates landscape preference as the modern expression of a genetic adaptation designed to help our ancestors settle in environments that support survival through offering the advantage of "seeing without being seen". First introduced by Appleton, the theory directly links the perception of our environment with our need to be protected from threats [7] by suggesting that the level of prospect (i.e., open and clear field of vision) and of refuge (i.e., places to hide) may significantly influence our responses. Although the original theory predicted a preference for habitats containing opportunities for both prospect and refuge, there is now some evidence to suggest natural environments with high levels of prospects and low levels of refuge also deliver restorative benefits [45].

\subsection{Limitations and Ecosystem Disservices}

If biophobia is the result of survival mechanisms selected over time as the most effective responses against the threats present in our environment, it should not be surprising that some of us view nature as full of dangers. Similarly, if not all natural environments are considered restorative then it naturally follows that some are not. In fact, and although some populations thrive in extreme ecosystems, "many natural environments, such as deserts, jungles, and mountains, may prove itself not only not restorative but actually dangerous, risky, and harmful" [10] (p. 3). Alongside the concept of ecosystem services, a new one, ecosystem disservice has been formulated to encompass all the ways in which natural environments can negatively affect human life [14].

Just as ecosystem services are the benefits provided by biodiversity to human welfare [14], ecosystem disservices cover the range of negative effects potentially delivered alongside those. As a complex social-ecological concept, it links both the environment and the populations who inhabit it. In the same way that ecosystem services are not provided equally to all populations, ecosystem disservices will be received differently by different people. For example, the inclusion of allergenic plants will provide an ecosystem disservices only to individuals who suffer from allergies to these specific plants. Similarly, individuals who might suffer from biophobic tendencies will perceive more ecosystem disservices from the implementation of natural areas, for example in the form of a loss of a sense of safety, or an increase in anxiety, or annoyance to the noise and smells, than individuals with more positive perceptions of nature. Conversely, ecosystem disservices can themselves contribute to biophobia through the promotion of negative interactions between human populations and natural environments. It is important to point out that, although the two concepts overlap and relate, they are distinctly different. For example, participants in the study of Maller and Farahani [15], although acutely aware of the various ecosystem disservices provided by the creation of a new biodiverse environment near their homes, generally supported the greening initiative.

However, studies have shown that natural scenes are unlikely to be perceived as restorative if they also feel unsafe, such as when they display obvious threats (a stranger lurking in the woods [38], or at night [46]). Accordingly, Gatersleben and Andrews, through repeated studies including the use of an online survey as well as a lab/field comparison, found that spaces with high refuge but low 
prospect, i.e., places were one could be hidden and not seen, did not carry the same restorative benefits than places with high prospect and low refuge [45]. Therefore, it is likely that elements of biophobia as presented here could limit the perception of any potential restorative benefits which might typically be expected from engaging with natural environments.

\subsubsection{The Fear of Wild Nature}

Although this review primarily focusses on built and mixed urban environments, it is helpful to consider nature as we perceive it as a gradient or continuum ranging from completely non-natural, fully built environments to fully natural, wild environments with no sign of human presence. To express the specific behavioural settings at each extreme of this gradient, an analytical review put together by Konijnendijk [8] on the human perception of wilderness uses the space-place perspective defined by Tuan [47]. According to Konijnendijk, built and mixed urban environments are more likely to be considered "places", fostering a sense of familiarity, shelter, comfort and security. On the other end of the continuum, many natural areas, particularly less managed, wilder ones can be perceived as "spaces" for urban dwellers, meaning these settings encourage exploration, adventure, freedom and a certain escape from the civilised society, while simultaneously promoting a sense of risk and vulnerability to danger through their proximity to the unknown. Ultimately, humans need both places (attachment) and spaces (freedom) [8,47].

This perspective is supported somewhat by Milligan and Bingley's exploration of young adult's perception of wild woodlands [46]. Through the quotes provided by the participants, woodlands are described both as a place to learn and explore physical skills and agility, as well as places of relative lawlessness where "if one of us got hurt, it'd take ages for one of us to run back" (p. 806) and there are "people getting buried [...] and stuff" (p. 807). In the same study, the authors also discuss the symbolic importance of wild woodlands as a source of sublime fascination deeply entrenched in the British collective unconscious through national folklore and myth. For example, woodlands heavily feature in many European fairy tales such as the ones from the brothers Grimm or Charles Perrault. Therefore, physical and psychological responses to these settings are likely to be heavily affected by cultural practices and beliefs which can be experienced at the local, national or international scale [46].

\subsubsection{Nature as Scary and Disgusting}

Some of the fears of nature most often reported are:

- Undesirable fauna: The presence of dangerous and/or unattractive animals including snakes, spiders and insects [15,48]. This fear is so integral to biophobia, several studies [5,27] have used it and its derivatives (dislike, disgust, fear, and perceived danger) as a proxy to study biophobia among various populations. This is critical as the expansion of urbanisation towards natural areas and the promotion of wilderness-related activities can create an overlap of habitats which has led to, for example, an increase in bear attacks worldwide [49].

- Allergies: Although the current evidence for the role of the outdoor environment to increase the occurrence of allergies is rather inconclusive [1], people suffering from allergies, particularly hay fever might find being outdoors at some time of the year particularly unpleasant.

- Poisoning: A review of over two thousand cases handled by the Poison Control Centre of Milan during a four year period showed that over eight thousands of them were related to the ingestion of mushrooms or plants. Although the majority of the cases were children under fourteen years of age, some of the most serious cases involved adults mistakenly identifying a poisonous species as edible [50]. Similarly, due to modern management techniques involving chemicals, living close to green spaces may be associated with an increased risk of being exposed to pesticides and herbicides [1].

- Vector-borne diseases: Closely related to undesirable fauna, vector-borne diseases are infections transmitted through the use of vectors such as mosquitoes, midges and flies. These include such diseases as malaria, dengue fever, chikungunya, and Zika, and together they cause more than a 
million deaths a year [51]. Although some of the main factors of propagation for these diseases are related to the quality of infrastructures in developing countries, in many cases proximity to vegetation and agricultural areas as breeding sites of vectors has also been found to be related with disease incidence [51].

- Crime: Beyond the fear of non-humans pests and predators such as undesirable fauna, green spaces have often been considered dangerous as the presence of vegetation can help dissimulate crimes and anti-social behaviours [52]. Interestingly, the presence of the stranger lurking in the woods led participants to the study to assess the restorative potential of a natural space as low as the one of a busy urban street, perhaps showing the specific response to perceived human threats over more non-human ones [38]. In wild areas, it has been suggested that this fear of strangers could be intensified by media representation as well as the often sensationalised reporting of murders and attacks [46,48].

- Injuries: Although the risk of serious or life-threatening injuries in urban green spaces is relatively low, studies do report an increased risk of accidents such as falls in areas with a greater number of public parks and playgrounds [1].

- Disorientation: Less likely in urban areas where space might be more restricted, the fear of disorientation or of getting lost is also a barrier to people visiting large scale outdoor spaces $[45,48,53]$.

\subsection{Delivery of Ecosystem Disservices}

One of the subtleties of the concepts of ecosystem services and disservices is that not all populations will perceive a service in the same way. It is therefore relevant to examine when ecosystem services become disservices and for whom.

\subsubsection{Location}

A good example presented by Lyytimaki et al. [14] is the provision of trees in cities. Trees are typically recognised to be great natural resources for human health, from their ability to reduce the urban heat island effect and lower perceived temperature in cities to their effect on crime rates and aggression levels [1,52]. However, as Lyytimaki et al. argue, residents of nearby houses might not feel very positive about such implementation if it reduces their view and the available sunlight coming into their home. Generally, the proximity of home can be critical for the perception of threats. In Maller and Farahani's investigation of urban residents' responses to greening interventions in Melbourne, participants expressed their support and acceptance of local wildlife, including species of undesirable fauna, as long as these animals were not found in their backyards or inside their homes [15].

\subsubsection{Populations}

Individuals who express a low preference for wild environments are inevitably less likely to engage with them. For example, Scopelliti et al. [36] found the perceived restorativeness of a natural area was evaluated as significantly lower by visitors of an urban plaza than by the visitors of the natural area itself. This issue can create biases if the sample chosen to participate in studies investigating the perception of certain environments does not include people who, for one reason or another, choose not to visit these environments.

Certain populations, particularly more vulnerable ones such as women and older people, but also those averse to risk-taking or sensation-seeking activities, may be less likely to engage with natural environments around them due to the fears presented above [6,53]. Adolescents have also been found to rate the perceived restorativeness of natural environments lower than the other age groups [17].

Perhaps relating to Orr's cultural perspective on biophobia as it pertains to our attachment to human comfort [7,32], the preferred restorative setting for many populations seems to be the home environment. For example, a study conducted by Berto [17] showed that, although older people assessed natural environments as more restorative than built ones, they still frequently chose 
domestic environments for their restorative experiences. Similarly, in a study looking at the restorative experiences individuals in deprived communities choose to engage in to cope with stress, Roe et al. [54] found that older people but also adults between 25 and 47 tended to stay at home as their favourite stress management method.

Visiting natural environments can promote a host of physiological and psychological benefits. But these benefits are not perceived or accessed equally by all populations. This is somewhat encapsulated by the element of Compatibility such as formulated into ART. Individuals which are afraid of nature or unlikely to engage with it for one reason or another are also less likely to receive any restorative benefit from engaging with it.

\section{The Health Benefits of Urban Built and Mixed Spaces: Evidence of Restorative Potential}

While much work has been conducted specifically on the importance of natural environments and elements, the restorative potential of the everyday urban environment has seldom been taken into account. Therefore this section presents the current evidence for the potential restorative effects urban population could perceive from built and mixed environments in the city. In doing so, it presents a preliminary answer to the questions: Can built and mixed urban environments be restorative? And for whom?

\subsection{Historical and Theoretical Perspective on the Health Effects of Urban Environments}

Negative perceptions of built and mixed urban environments are almost as old as cities themselves. In a review of the links between the landscape and health [3], Prof. Ward Thompson presents a thorough history of human perceptions of green spaces and cities. She notes that the ancient Greeks were aware of the importance of green spaces for an urban life, choosing to locate their cities in sites where clean water and natural beauty were available. Romans mostly continued that trend but, even then, Pliny the Younger is reported to have written about the "profound and undisturbed retirement" he experienced in his villa in the countryside by putting distance between himself and "the business of the town and the interruption of troublesome clients". His contemporary, Martial, coined the phrase rus in urbe to express the desired inclusion of countryside elements into the urban context [3].

The health of urban populations became a critical issue for city planners once the Industrial Revolution had started and the rural exodus alongside it brought more and more people into the city to fill the factories. Major cholera, typhoid and tuberculosis epidemics threatened the cramped and overcrowded neighbourhoods where the industrial workforce was housed. This prompted authorities to start considering green spaces as necessary to improve health conditions and cities, thus initiating the concept of parks as "the lungs of the city" [3]. Similarly, Frederick Law Olmsted and Calvert Vaux famously designed Central Park as a way to provide relief to the residents of New York city, following the idea that:

"A man's eyes cannot be as much occupied as they are in large cities by artificial things or by natural things seen under obviously artificial conditions, without a harmful effect, first on his entire mental and nervous system and ultimately on his entire constitutional organisation" Olmsted, 1886, in [3] (p. 192)

He listed these "harmful effects" as "excessive nervous tension, over-anxiety, hasteful disposition, impatience and irritability" (Olmsted, 1886, in [3] (p. 192)). According to him, the only way to counteract these effects was through the use of an Arcadian landscape, a pleasing rural scenery masking the buildings around it and displaying no obvious sign of human intervention [3]. This myth of Arcadia, originally from ancient Greece, was brought back into popular culture in the Renaissance through music, poetry and paintings. Although originally meant to designate the wild landscape where Pan and his dryads reigned, it came back in the shape of a pastoral landscape softly shaped by humans but not corrupted by civilization. This utopic idealised landscape seemed therefore to have been in itself created as a way to offer an escape to inhabitants of cities to an environment which 
was similarly tamed and humanised through the use of agriculture, but which was also perceived as simpler and, ultimately, healthier. As a pastoral landscape, it is placed somewhere in the middle of the gradient between completely wild and completely built environments.

Although the cities of Olmsted were quite different from the amenity-centred modern metropolis of today, this perception of cities as overloaded with stimuli that leads to saturation is still alive and well. In fact, it is this same perception which has led to the perpetuation of the urban-bad/nature-good dichotomy. Therefore, built and mixed urban environments are typically associated with the high presence of information and stimuli such as crowds, noise [10,23], but also pollution and little aesthetic value. On an epidemiological level, cities are also seen as foci of infections in part due to the density of human populations. In developing countries, rapid urbanization has had an impact on the pattern of infectious diseases through the development of new built environments in forested areas, overcrowding, and precarious urban and housing infrastructures [51]. The high temperature of cities as a result of the heat island effect created by the modification of land surfaces was also found to play a major role in some vector-borne diseases transmission [51]. On a cognitive level they are also considered to require more top-down processing than natural environments, which necessitates more directed attention and in turn generates more cognitive fatigue [55].

\subsection{Urban Environments in Restoration Theories}

So, can built and mixed environments be restorative in theory? Out of the four pathways linking landscape and health only the physiological pathway strictly requires a natural environment, as built settings can also provide opportunities for social contact and physical activity. But what about the psychological one?

Within ART, the Kaplans considered that the urban lifestyle might be a major cause of the depletion of directed attention. By contrast to the city, a natural environment is considered as less demanding which allows individuals to switch into effortless attention and provides a rest for the directed attention. But none of the environmental characteristic they provide to describe restorative settings, except perhaps fascination, strictly requires the presence of natural elements.

Similarly, Ulrich considered the built urban environment too complex and too high in arousal to enable us to relax [43]. However, he also points out that aesthetically pleasing built settings containing water and prominent amounts of vegetation might carry a restorative influence similar to more natural scenes [31,43]. Furthermore, following arousal theory, he also admits that individuals suffering from excessively low arousal or chronic boredom might benefit from being exposed to lively and stimulating urban views [43].

Finally, Appleton's prospect-refuge theory specifies the physical structure of an environment, as it relates to views and openness, rather than its specific elements. Therefore, by considering solely the criteria formulated by ART, PET and prospect-refuge theory, it is also conceivable that some urban settings might be used as restorative environments $[10,36]$.

\subsection{Review of Evidence}

Recently, some empirical studies have been carried out on the restorative potential of built and mixed urban environments. Most notably, Karmanov and Hamel [9] have found that their participants who watched a short video of an urban residential environment reported a decrease in anger and tension comparable to the one experienced by the participants who watched a similar video but of a natural environment. Similarly, while exploring the restorative potential of urban leisure settings, Troffa and Fornara [19] found that a green urban park rated similarly to two attractive built environments. This equality of restorative potential was also found in Scopelliti and Giuliani's study, in which they asked residents of different ages and backgrounds to list restorative experiences they might engage in [22]. Indeed, in this case, natural settings were not cited more often than built or mixed ones. 
However, when comparing a historical, mostly built urban environment to a forest, Stigsdotter et al. [24] found that neither environment had any measurable physiological effect on heart-rate variability or blood pressure of visitors, but that the forest would still be assessed as having the higher perceived restorativeness. This finding was also supported by Scopelliti et al. [36] who compared the perceived restorativeness potential of a completely built historical plaza and that of a large public park and found that the more natural environment generally scored higher. Generally, it seems the presence of vegetation can still significantly improve the restorative potential of an urban environment $[10,21,25]$.

Finally, not comparing with a natural environment, San Juan et al.'s participants reported a better psychological state after spending some time in an urban square [10]. Although their initial levels of attentional fatigue and emotional distress were shown to be low, the students had worked an average of $4 \mathrm{~h}$ previous to the experiment and the benefits they received from their visit to the built space were found to include reduced anger, hostility, tension, anxiety, fatigue and stress, and increased happiness. They also explored the importance of environmental features for restoration by comparing two different public squares alongside some of ART's criteria (greenness, presumably as a proxy to soft fascination, and mystery, which is more often associated with the Kaplan's preference matrix rather than ART [2]. However, they could not find any effect from these variables which suggests the restoration provided by built environments might follow a different framework than the one articulated by ART and PET.

\subsection{Populations More Likely to Use Built and Mixed Urban Environments for Restoration}

Although some of the studies reported here were carried out using the convenience sample of students in the field of psychology $[9,10,23,24]$, many others have focussed on the specific populations which might generally benefit from the type of restoration provided by urban built and mixed environments.

Generally, teenagers and adolescents have been the focus of many studies and their preference for built environments over natural ones has often been noted. In a comparison of perceptions of nature's restorativeness across age groups, Berto found that adolescents (11-14 years old) were the ones to prefer city streets and housing to natural environments the most [17]. Similarly, in their survey of 450 eight-grade students, Bixler and Floyd [7] found that adolescents who reported negative perceptions of wildlands also reported an increased preference for social indoor recreation, manicured park paths, urban paths and biology lab sites with clear water. Although this alone is not enough to conclude theses places might be restorative for them, the link between preference and restoration previously mentioned suggests they could be. Generally, adolescents seem to value settings such as urban centres which offer opportunities for social interaction and promote affiliation and identification with a group [17].

Similarly, the importance of social contact as a drive for visiting specific environments has also been studied in the case of older people. For example, Gardner [56] found that for people over 75 year old, third places such as public parks but also social centers like shops and cafes, churches; thresholds such as front yards and balconies; and transitory zones such as streets and pavements could all support significant social interactions.

Furthermore, in an urban context and with the current development of technologies, most contact with natural environments must now be through deliberate choices and self-selected recreational activities [32] and "if the environment is negatively perceived, activities that occur within it may also be avoided" [7]. Conversely, when investigating restorative experiences, as opposed to the characteristics of the environment alone, Scopelliti and Giuliani found that natural environments were not evaluated as more restorative than built or mixed ones. Indeed, the latter might in fact be considered more accessible and preferable for engaging in social activities during leisure time, particularly if that time is limited by other constraints [22]. This finding was supported by Staats et al. [23] who found a significant effect of personal and contextual factors such as being alone or in company or the existing 
level of attentional fatigue on the perceived restoration likelihood of built spaces (in this case a café in a city centre).

Finally, other populations such as the ones most afraid of nature as presented above might also be more likely to choose built and mixed urban environments to restore their cognitive and emotional capacities.

\subsection{Specific Urban Environments}

Although many studies on the benefits of natural areas rely on the use of urban "busy street" environments as surrogates to represent the whole variety of urban settings $[23,24,33,38]$, the research presented in this section has explored the specific qualities of mixed and built urban environments which may promote restoration.

Most notably, Hidalgo et al. [20] conducted several studies to assess the aesthetic qualities of several types of mixed urban environments in Spain and Italy. Although they were primarily looking at people's aesthetic responses, they also asked residents of Malaga (Spain) and Padova (Italy) to assess the perceived restorativeness of these settings and found a high correlation between the two judgements, which they interpreted to mean that the perceived restorativeness could also predict aesthetic appreciation [20]. They found the most attractive urban environments to be:

- Cultural-historical places/landscapes which they define as "representative and/or emblematic places of the city, linked strongly with its historical-cultural development" (p. 117). Cultural-historical settings were also explored by Scopelliti et al. [36].They found that an attractive historical plaza in Rome could rate as high as an urban green space in perceived restorativeness potential. Much like Hidalgo et al. [20], they related this effect to, in part, the aesthetic value of such environments, but also investigated the individual components of ART. In their study, the historical plaza visitors rated their surroundings highly in terms of fascination, compatibility and, to a lesser degree, extent. The element of being away did not seem to contribute to the overall perceived restorativeness of the environment, but they do warn "the measure of being away in the Perceived Restorativeness Scale does not include items referring to feeling away in ancient times or in a different world, which are all relevant aspects for historical environments" [36] (p. 9).

- Recreational places for leisure and/or walking such as urban parks, squares and public open spaces designed in order to be used by citizens with such aims. These are considered mixed environments with various degrees of greenness such as in the studies by San Juan et al. [10] and Subiza-Pérez [25], who also specifically investigated public squares as centres of a city's social life. - Panoramic places such as favoured places in the city offering a wide sight of large areas or of the whole city. The restorative potential of panoramic places has been found in at least one other study [19] and is in line with Appleton's Prospect-Refuge theory which states our preference for high-prospect, low-refuge environments [2].

Residential areas, as mixed environments, have also been found to sometimes perform better than more natural environments, as is the case in the study of neural responses of older people walking in various urban environments, where a quiet residential street with front gardens yielded less frustration than a medium-sized park in Edinburgh [55]. Similarly, the stimulus used in the study from Karmanov and Hamel [9] was a video of a recently built neighbourhood in the Netherlands, with houses built alongside canals. In this case, the aesthetic aspect of the environment might be more salient, with complex architectures and facades being able to produce similar responses to natural scenes [21]. Additionally, as highlighted by Ulrich in PET, the presence of water could also have influenced the participants' perceptions [42].

In conclusions, it is possible to extend theories of restoration to encompass the study of built and mixed urban environments. Using these criteria, some settings, particularly social or aesthetically pleasing ones, have been found to be preferred by some urban dwellers for their restoration needs. However, in most cases, the presence of vegetation still plays a significant part on people's responses. 
Indeed, none of the studies reported any preference for purely built environment. Instead, urban vegetation is appreciated for its aesthetic value and as a symbolic element of the city's identity [57]. Nevertheless, it is possible the type of restoration experienced in built and mixed settings follows a different framework than the ones articulated by ART, PET and prospect-refuge theory.

\section{Discussion}

There is now a substantial body of research on the benefits of urban green spaces on human health [1] but this rarely considers the potential disservices brought on by the proximity of natural areas or the populations who might not benefit from this proximity. Even more problematic is the lack of research on the restorative potential of built and mixed urban settings, which are now the main environment of the majority of the world's population.

\subsection{Modern Biophobia}

A growing number of studies are now looking at ecosystem disservices or the ways in which natural environments are not always appreciated. Is this lack of appreciation a result of modern biophobia such as the one described by Ulrich [31] and Orr [32]?

Many of the dissonances between the theoretical and actual appreciation of nature are linked to the evolutionary assumptions which underlie theories of restoration such as the ones presented in introduction, ART, PET and Prospect-refuge. Indeed, these theories are formulated to explain immediate or innate responses to environments which support, or not, human survival, either through a clear path to resources (ART), an absence of threat (PET) or the ability to protect oneself against these threats (Prospect-refuge). However, built and mixed urban environments provide us with plenty of resources and protection against external threats by being specifically designed to support human (and solely human) survival so why are they not considered more restorative than natural ones?

It is generally considered that the time we spent embedded in our natural environment (300,000 years, from the first trace of Homo Sapiens) is significantly longer than the time we spent living in cities (since $3000 \mathrm{BC}$, approx.), and that the process of natural selection which guaranteed the survival of these adaptative traits takes too long for us to have significantly adapted to living in cities. These assumptions are now being criticised for their dismissal of cultural and personal differences $[2,12,13]$. Furthermore, the development of modern adaptative traits such as lactose tolerance suggest that physiological and psychological evolution can actually happen within a restricted time span [13].

Similarly, according to Ulrich's PET, recovery from stress requires specific environmental features which are able to trigger positive affective responses, the most critical of these being the absence of threat [13]. In Ulrich's view, natural environments are the only ones capable of generative this type of positive affective responses, but the studies included in the first part of this review clearly show this absence of threat is not perceived by everyone in the same way. Arguably, this perspective of natural environments being unthreatening is quite Western and only really applies to developed countries which have successfully tamed their surroundings and gotten rids of their large predators. Presumably, most natural settings were considered dangerous until the development of cities, and urban environments would have certainly been considered safer than most natural environments for quite a long time.

Although it appears from the present review that specific populations such as teenagers and elderly people who exhibit the most biophobic behaviour are also the ones more likely to receive restorative benefits from mixed and built settings, more research is needed to understand the links between these two concepts. 
Mitigating Biophobia

Although some elements of response have been formulated to understand the formation of biophobic behaviours, ultimately more research is needed [7]. One factor which is known to mitigate some aspects of cultural biophobia is the importance of childhood experience $[5,6,27,28,48]$.

Most strikingly, Ward Thompson et al. [6] conducted an exploration of two independent samples (one Scottish, the other English) of parks visitors, looking not only at perceptions but also behaviours and attitudes. They found that the most significant predictor of how often participants visited green spaces in their adult life was the frequency of green space visit in their childhood. Interestingly, a low frequency of childhood visit was a stronger predictor of infrequent visits to green spaces as adult than the other way around. In other words, although not all children who visit natural environments frequently will continue to visit them as often as adults, children who rarely visit them will most likely continue to not visit them as they grow up [6].

This result could potentially have been explained by the importance of familiarity with a given environment for the appreciation of it. However, familiarity is not a stable predictor for preference or restoration as it can also breed contempt. For example, in a survey of Spanish and Italian urban dwellers Hidalgo et al. found no influence of familiarity (measured in years spent in the city) on the residents' aesthetic perception of their environments [20]. This was also the case for Scopelliti et al. who found no influence of familiarity on the perceived restorative potential of built and natural environments [36]. By contrast, looking at the mood of older people walking in various mixed urban environments, Tilley et al. [58] found familiarity to be an important aspect in promoting positive mood states, by triggering past positive experiences and memories.

Although the studies included in this review (particularly in the third section) showed the potential restorative benefits of built and mixed environments, it is clear natural areas should still be preserved. Indeed they deliver many more ecosystem services to the population than through restoration alone. Studies comparing the perceived restorativeness of natural and attractive built scenes also tend to show the largely superior potential of natural areas, for the right population [36] or for high levels of attentional fatigue [23,33]. Therefore, a complete extinction of experience is also not desirable. The children of today who are already suffering from biophobia will grow up into adults and educators who will continue to perpetuate these negative responses to the natural environment [5]. Therefore, it is important to understand their needs and perception as well as to provide safe and attractive opportunities for them to engage with nature.

Finally, it seems important to point out that fearful encounters are not always negative [45]. In fact, some scary experiences can generate an improved sense of self confidence by forcing people to face their fears and discovering their own resources [53]. These benefits, however, could be categorised as instorative rather than restorative, as they do not strictly entail the recovery of depleted resources but rather the creation of new skills or the strengthening of existing capabilities [11].

\subsection{Recommendations for Further Research}

Although most of humanity now lives in cities with a wide variety of mixed environments, many studies still operate by forcing a dichotomy between urban and natural settings [9,20,23,24].

Some of the reasons behind this can be related to the limitations of natural empirical research where many variables are outside of the control of investigators. Such research designs often pushed researchers to set up experimental conditions which are contrasted enough to elicit significant responses. Similarly, Scopelliti suggests that the aim of many early studies in the field was to develop a valid measure of restorativeness. Therefore, their selection of environmental stimuli "presumably reflected the willingness to detect the properties of the instrument with respect to environments showing a strong differentiation" [22] (p. 433). But if the urban environment is chosen specifically for its perceived contrast with the natural environment, then aren't the responses observed necessarily part of a confirmation bias? For example, recently Staats et al. [23] have pointed out that studies had a tendency to choose images of recreational and leisure areas as a surrogate for the nature experience, 
and images of transport areas such as "busy streets" for the urban experience. Using this approach, natural environments are routinely declared healthier and better for us than built environments [18]. This issue of environmental sampling is of critical importance for the validity of research as, by using extremes settings as experimental stimuli, researchers overlook that the wide majority of existing environments are now mixed, made out of built elements and vegetation altogether.

Another major threat to the validity of these studies is their population sampling method, sometimes by solely focussing on natural areas' visitors at the expense of non-visitors [7]. For example, a recent study on a wild urban park in Seattle found that $95 \%$ of its visitors had meaningful interactions with nature which depended on the park's wilderness. They concluded that wilderness was vital for human health. The limitations of the study which resulted from only being able to survey people who were already visiting the park are not discussed, with the exception of a comment on the lack of (ethnic) diversity of the participants [59]. Therefore, it is unclear if the same wilderness would mean quite the same thing to the people living around the park but who did not visit it. For example, the findings from Scopelliti et al. [36] suggest the visitors to the park had a much higher idea of its restorative potential than those who choose to visit urban spaces instead.

In the original essay by Orr [32], the biophobic point of view is embodied by Woody Allen's "Nature and I are two" quote. Orr asks the readers "Is it OK that Woody Allen feels no kinship with nature?" (p. 416). One shudders at the thought of what a negative answer to that question would entail, as what people feel or don't feel surely should remain their own prerogative. However, this is exactly what Orr does, by accusing Woody Allen of being a "freerider" on environmental issues that his biophobia prevents him to care about while still profiting from the clean air and clean water that the work of others, less biophobic people, protects. Further on, after linking biophobia to psychiatric pathologies such as misanthropy and sociopathy, he also compares this attitude to "the result of deformed childhoods that create unloving and often violent adults" [32] (p. 420).

Orr also formulates the thought that the modern capitalist, technology-obsessed society of the Western World conceals contempt for unaltered life and nature, under the guise of progress and economic growth [32]. One could argue in response that economic growth is perhaps more likely to support a population's health (through access to care, education and healthy food) than the sole presence of a green space nearby. Isn't the environmental conservation perspective the one concealing contempt for populations understandably attached to their material safety?

There is no doubt the political agenda of some environmental sciences such as environmental psychology has been overwhelmingly in favour of nature conservation, and this might have created a bias in favour of publishing more nature-friendly results. Claims of the universal tendency to biophilia have possibly been "fuelled by the concern that we would lose an argument for nature preservation if it would turn out that positive human affective attitudes to nature are not driven by a deeply engrained connection with nature" [13] (p. 267). But, at least in social sciences and humanities and in the Western world, this only creates an echo-chamber whereby people who already feel connected to nature continue to produce evidence that this connection is healthy, whereas people who do not share this connection are, at best not included in the conversation and at worst negatively judged for their perceptions as being a sign of mental dysfunction. This divergence of perspectives can for example be observed in Hofman et al.'s comparison of planners and residents' perceptions of urban natural areas, which showed experts valued wildness much higher than non-experts who instead preferred artificiality [60].

A fertile direction for new research might be to leave behind the dichotomy between natural and built environments and instead to take into consideration this idea of nature being perceived as a gradient or continuous spectrum between completely non-natural and natural, such as expressed by Konijnendijk [8]. This change of perspective could particularly be of use when attempting to measure produced and natural capital [61] as what matters more to human well-being may be "mixed" rather than purely "natural" capital. Similarly, by focussing in more details on mixed environments 
it might be possible to find how to maximise the delivery of ecosystem services while minimizing ecosystem disservices.

Finally, the present review was carried out over a limited amount of time and is based on data collected over restricted search terms on a single academic publishing platform. Future research on these complex topics should endeavour to include the use of Web of Science and SCOPUS search engines to enrich the number of publication as well as use other searching terms, such as "fear of nature" or "nature connectedness" to extend the results.

\section{Recommendations for Design and Planning}

Past studies have discussed the importance of biophilia for the creation of sustainable and resilient cities [62]. Examples of interventions such as nature-based solutions and green infrastructures abound in the literature, but these recommendation do not always take into account potential ecosystem disservices or accessibility to more biophobic urban dwellers. In order to address these issues and ensure future interventions aiming at creating liveable and sustainable mixed urban spaces are successful for both humans and non-humans, here are some of the recommendations which have been formulated in the literature. These specifically regard the inclusion of green spaces within the built urban framework, for the benefit of urban dwellers. Some of these recommendations cover elements of design at various scales, whereas other encompass critical social interventions as well.

\subsection{Design Interventions}

These interventions cover ideas and advice for the implementation of natural areas which can be appreciated, used and enjoyed by all, from the city to the site scale.

\subsubsection{Green Space Provision}

In their survey of Japanese children, Soga et al. [5] defined the degree of urbanisation of the children as the proportion of impermeable surface within a $500 \mathrm{~m}$ radius around the school. They found this variable to be positively correlated with the children's biophobia, highlighting the importance of green spaces being in close proximity to home or work for the perpetuation of nature experiences. Similarly, Thwaites et al. recommend a network of small pocket-parks, with their own identities but connected into a coherent whole to offer different urban dwellers a variety of restorative experiences suited to their individual needs [63].

However, and even if the implementation of more urban green spaces help combat the heat island effect, it could also promote the replication of vectors such as mosquitoes and ticks, and increase their likelihood of contact with the human population $[64,65]$. Although most agree that good drainage and water storage systems are critical to prevent the creation of stagnant pools of water to act as breeding grounds for the vectors, some more research is needed to understand the particular types of landscape design which can increase or reduce the reproduction, survival and feeding of vectors in built and mixed urban areas [51,64,65].

\subsubsection{Detailed Design}

Tackling the issue of perceived safety is critical at this scale, which covers most of the more immediate experiential aspects of visiting a particular environment. Following their interview with communities, Maller \& Farahani [15] recommend the use of "wide paths" in order to limit the risks of spontaneous interactions with undesirable fauna. These paths can also ensure a greater accessibility for older and disabled people. To limit the likelihood of injuries on playgrounds, impact-absorbing surfaces should also be preferred [1]. 
Visibility

Following prospect-refuge theory, and the idea that fear of crime is higher where vegetation blocks views [52], a majority of open views are recommended. These can be achieved with the help of visibility-preserving forms of vegetation, such as grassy areas, low growing shrubs and widely spaced, high canopy trees [52]. Strictly non-toxic plants should be used [50].

To counter any fear of disorientation in larger areas, clear and coherent signage as well as visual cues can provide effective wayfinding information to counter the fear of getting lost [48].

Similarly, ensuring sufficient lighting can go a long way in providing a greater sense of safety all-year round. Natural areas are often limited in that regard, as artificial lighting can have disastrous consequences for the flora and fauna through the creation of light pollution. "Soft" interventions, such as automatic lights prompted by motion detectors, or low-voltage ground lighting might be preferred.

\section{Wilderness}

Studies investigating human perceptions of wild spaces indicate that the majority of us might have a preference for medium-wild environments. Indeed, some studies have shown that restorative benefits are increased for participants visiting a "tended" forest as opposed to a wild one [66,67]. For example, although path width, slope, accessibility and vegetation types were chosen equal, Martens et al. found a stronger change in affect for participants viewing images of a commercial forest displaying clear signs of human presence such as piles of cut logs besides the paths, than for participants viewing images of a "wild" forest which had not been used commercially for over 6 years [66]. Similarly, Hofmann et al. have found that landscape planners expressed a higher preference for more "natural" settings than residents who instead preferred more "artificial" green spaces [68].

Overall, existing research suggests that "a visible and positive human influence is important" for potential users to accept natural areas [60] (p. 304). The aim here is not to promote plastic lawns and the overuse of non-native species, but rather to balance the wild with the managed in order to provide inclusive and accessible spaces for all. To achieve this, and although they come from a specific cultural context, designers could find inspiration in traditional Japanese tea gardens which are particularly designed to portray a pleasing dialectical interaction between the natural and the artificial, through the use of scattered artefacts and carefully curated vegetation [69].

\subsubsection{Maintenance}

Beyond the design and creation of a new urban green space, its maintenance can also make a strong impact on visitors' perceptions. A clean and well-maintained area is the clearest sign of safety, under the guise of human presence [52], as was pointed out by several studies around the world $[1,60,70]$. A lack of visible traces of vandalism will indicate the safety from human danger, whereas well-maintained paths and areas of manicured vegetation will also express the level of domestication of the site which will in turn feel more in line with its urban surroundings.

As a long-term investment and practice, maintenance may be the mainstay of the current challenges of urban spaces, as it is subject to decay and depreciation. Sometimes, a choice needs to be made between low maintenance plants or surfaces, and promoting more biodiversity [71]. Designers and planners facing this choice must carefully weight the ecosystem services and disservices thus provided to the local population. The management practices used thereafter should be in line with the original design and be kept up with in order to ensure full accessibility and inclusivity.

\subsection{Social Interventions}

These recommendations encompass all levels of social outreach and engagement, from before a project is implemented to after its implementation. It is now well accepted that in order to achieve sustainability in any type of local intervention, residents must get involved. 


\subsubsection{Participation}

Of course, this starts before a project is being built, by engaging residents in discussions with the designers and developers to understand how an area is or could be used and to address the concerns of the people who will use it. Resident communities are a vast source of knowledge, particularly regarding local pests and undesirable fauna as well as the perceived safety of an area [15].

\subsubsection{Social Programming and Activities}

By investigation the influence of parental discourse for children's perceptions of nature, Soga et al. [5] demonstrated the importance of engaging entire families in interactions with their environment. By organising multi-generational activities, as well as educational activities for the children, a greater sense of nature connection can be fostered.

\subsubsection{Education}

Adolescents such as the surveyed by Bixler and Floyd [7] or [46] were already able to formulate their negative perceptions of wilderness and how it impacted their choice of recreational activities from a young age. The promotion of outdoor programs for youth which demonstrate the rewards of being in wildlands while offering appropriate interpretation of anything unpleasant or scary, has often been cited as a way to help young people to develop more positive perceptions and attitudes towards natural environments $[7,46,48]$.

Beyond just spending time in nature, several studies also highlight the importance of factual and behavioural education for the mitigation of biophobic behaviours [5,27]. This education can either be centred on increasing knowledge and understanding of specific issues in biology or ecology, or focus on encouraging children's ability to self-assess risks through the implementation of unstructured and unsupervised play [46]. Indeed, it is not enough to provide an abundance of green spaces if children and young adults are not able to explore and appropriate the space themselves.

\section{Conclusions}

Implementing natural elements in urban contexts offer many benefits, physiological, social, physical but also psychological. However, some people still experience barriers to visiting or engaging with more natural types of environments and this can impede them receiving any benefit from such interventions. Instead, they fulfil their needs for restoration and relaxation in other ways, by visiting built and mixed urban environments such as historical districts, urban plazas and panoramic places or simply staying indoors.

Although it is important to continue to study all the ways in which the provision of healthy natural environments can support human health, it is equally important to acknowledge that these benefits might only be accessible to people with a certain existing predisposition towards nature which might not form the majority. In order to formulate, design and implement successful and sustainable interventions to develop a liveable green urban environment, it is important to keep in mind that the interest and health of the actual target population should always remain the priority. Therefore, understanding the needs of urban dwellers, as well as their aversions, is critical in order to address the barriers, real or perceived, which keep them from engaging with nature.

The existing connection between people and nature could potentially be preserved by encouraging children to engage with the natural environment, but the innate and genetic basis for biophobia might not so easily be tackled. The focus should then be on the creation of mixed environments where nature is present but not threatening and balanced with the presence of restorative built elements. Ultimately, more research is needed to understand modern biophobia and the emerging patterns of connection with our daily environments. 
Funding: This research received no external funding.

Acknowledgments: The author wishes to thank Catharine Ward Thompson (The University of Edinburgh) for her support and comments on an earlier draft and Philippa Coles (MSc Landscape \& Wellbeing, The University of Edinburgh) for providing some of the inspiration and references for this paper in her MSc essay for the Landscape \& Wellbeing: Theoretical Foundations course. Many thanks also to the journal reviewers who provided thorough constructive and helpful feedback.

Conflicts of Interest: The authors declare no conflict of interest.

\section{References}

1. WHO. Urban Green Spaces and Health: A Review of the Evidence; World Health Organization: Geneva, Switzerland, 2016; pp. 1-92.

2. Hartig, T.; Van Den Berg, A.A.E.; Hagerhall, C.M.; Tomalak, M.; Bauer, N.; Hansmann, R.; Ojala, A.; Syngollitou, E.; Carrus, G.; Herzele, A.V.; et al. Health benefits of nature experience: Psychological, social and cultural processes. In Forest, Trees and Human Health; Nilsson, K., Sangster, M., Gallis, C., Hartig, T., De Vries, S., Seeland, K., Schipperijn, J., Eds.; Springer Science + Business Media B.V.: Berlin, Germany, 2011; Chapter 5, pp. 127-168. [CrossRef]

3. Ward Thompson, C. Linking landscape and health: The recurring theme. Landsc. Urban Plan. 2011, 99, 187-195. [CrossRef]

4. Mitchell, R.J.; Richardson, E.A.; Shortt, N.K.; Pearce, J.R. Neighborhood Environments and Socioeconomic Inequalities in Mental Well-Being. Am. J. Prev. Med. 2015, 49, 80-84. [CrossRef] [PubMed]

5. Soga, M.; Evans, M.J.; Yamanoi, T.; Fukano, Y.; Tsuchiya, K.; Koyanagi, T.F.; Kanai, T. How can we mitigate against increasing biophobia among children during the extinction of experience? Biol. Conserv. 2020, 242, 108420. [CrossRef]

6. Ward Thompson, C.; Aspinall, P.; Montarzino, A. The Childhood Factor: Adult Visits to Green Places and the Significance of Childhood Experience. Environ. Behav. 2008, 40, 111-143. [CrossRef]

7. Bixler, R.D.; Floyd, M.F. Nature is scary, disgusting, and uncomfortable. Environ. Behav. 1997, $29,443-467$. [CrossRef]

8. Konijnendijk, C. Between fascination and fear-The impacts of urban wilderness on human health and wellbeing. Soc. Tidskr. 2012, 89, 289-295.

9. Karmanov, D.; Hamel, R. Assessing the restorative potential of contemporary urban environment(s): Beyond the nature versus urban dichotomy. Landsc. Urban Plan. 2008, 86, 115-125. [CrossRef]

10. San-Juan, C.; Subiza-Pérez, M.; Vozmediano, L. Restoration and the city: The role of public urban squares. Front. Psychol. 2017, 8, 1-13. [CrossRef]

11. Hartig, T. Three steps to understanding restorative environments as health resources. In Open Space People Space; Ward Thompson, C., Travlou, P., Eds.; Taylor \& Francis: Milton Park, UK, 2007; Chapter 12, pp. 163-179.

12. Joye, Y.; de Block, A. 'Nature and I are two': A critical examination of the biophilia hypothesis. Environ. Values 2011, 20, 189-215. [CrossRef]

13. Joye, Y.; van den Berg, A. Is love for green in our genes? A critical analysis of evolutionary assumptions in restorative environments research. Urban For. Urban Green. 2011, 10, 261-268. [CrossRef]

14. Lyytimäki, J.; Petersen, L.K.; Normander, B.; Bezák, P. Nature as a nuisance? Ecosystem services and disservices to urban lifestyle. Environ. Sci. 2008, 5, 161-172. [CrossRef]

15. Maller, C.; Farahani, L. Snakes in the City: Understanding Urban Residents' Responses To Greening Interventions for Biodiversity. In Proceedings of the State of Australian Cities National Conference (SOAC 2017), Australian Cities Research Network, Adelaide, Australia, 28-30 November 2018; pp. 1-10.

16. Weber, A.M.; Trojan, J. The Restorative Value of the Urban Environment: A Systematic Review of the Existing Literature. Environ. Health Insights 2018, 12, 1-13. [CrossRef] [PubMed]

17. Berto, R. Assessing the restorative value of the environment: A study on the elderly in comparison with young adults and adolescents. Int. J. Psychol. 2007, 42, 331-341. [CrossRef]

18. Van den Berg, A.; Koole, S.; Vanderwulp, N. Environmental preference and restoration: (How) are they related? J. Environ. Psychol. 2003, 23, 135-146. [CrossRef] 
19. Troffa, R.; Fornara, F. The relationship between restorative components and environmental preference in natural and built leisure environments. In Espacios Urbanos y Sostenibilidad: Claves Para la Ciencia y la Gestión Ambiental. Libro de Actas del XI Congreso de Psicología Ambiental; Fernández-Ramírez, B., Hidalgo, M.D.C., Salvador, C.M., Martos, M.C., Eds.; Universidad de Almeria: Almeria, Spain, 2011; pp. 231-237.

20. Hidalgo, M.C.; Berto, R.; Paz Galindo, M.; Getrevi, A.; Galindo Galindo, M.; Getrevi, A. Identifying attractive and unattractive urban places: Categories, restorativeness and aesthetic attributes. Medio Ambiente Comport. Hum. 2006, 7, 115-133.

21. Lindal, P.J.; Hartig, T. Effects of urban street vegetation on judgments of restoration likelihood. Urban For. Urban Green. 2015, 14, 200-209. [CrossRef]

22. Scopelliti, M.; Vittoria Giuliani, M.; Giuliani, M.V. Choosing restorative environments across the lifespan: A matter of place experience. J. Environ. Psychol. 2004, 24, 423-437. [CrossRef]

23. Staats, H.; Jahncke, H.; Herzog, T.R.; Hartig, T. Urban options for psychological restoration: Common strategies in everyday situations. PLOS ONE 2016, 11, e0146213. [CrossRef]

24. Stigsdotter, U.K.; Corazon, S.S.; Sidenius, U.; Kristiansen, J.; Grahn, P. It is not all bad for the grey cityA crossover study on physiological and psychological restoration in a forest and an urban environment. Health Place 2017, 46, 145-154. [CrossRef]

25. Subiza-Pérez, M.; Vozmediano, L.; San Juan, C. Welcome to your plaza: Assessing the restorative potential of urban squares through survey and objective evaluation methods. Cities 2019. [CrossRef]

26. Taylor, L.; Hochuli, D.F. Defining greenspace: Multiple uses across multiple disciplines. Landsc. Urban Plan. 2017, 158, 25-38. [CrossRef]

27. Hosaka, T.; Sugimoto, K.; Numata, S. Childhood experience of nature influences the willingness to coexist with biodiversity in cities. Palgrave Commun. 2017, 3. [CrossRef]

28. Zhang, W.; Goodale, E.; Chen, J. How contact with nature affects children's biophilia, biophobia and conservation attitude in China. Biol. Conserv. 2014, 177, 109-116. [CrossRef]

29. Kellert, S.R.; Wilson, E.O. (Eds.) The Biophilia Hypothesis; Island Press: Washington, DC, USA, 1993 ; p. 496.

30. Bell, S. Landscape: Pattern, Perception, and Process; Taylor \& Francis: Milton Park, UK, 2012; p. 360.

31. Ulrich, R.S. Biophilia, Biophobia, and Natural Landscapes. In The Biophilia Hypothesis; Kellert, S.R., Wilson, E.O., Eds.; Island Press: Washington, DC, USA, 1993; pp. 31-42.

32. Orr, D. Love It or Lose It: The Coming Biophilia Revolution. In The Biophilia Hypothesis; Kellert, S.R., Wilson, E.O., Eds.; Island Press: Washington, DC, USA, 1993; pp. 414-440.

33. Hartig, T.; Staats, H. Linking preference for environments with their restorative quality. In From Landscape Research to Landscape Planning: Aspects of Integration, Education and Application; Tress, B., Tres, G., Fry, G., Opdam, P., Eds.; Springer: Berlin, Germany, 2005; pp. 279-292.

34. Hartig, T.; Korpela, K.; Evans, G.W.; Gärling, T. Validation of a Measure of Perceived Environmental Restorativeness. J. Environ. Educ. 1996, 32, 1-64.

35. Wilkie, S.; Stavridou, A. Influence of environmental preference and environment type congruence on judgments of restoration potential. Urban For. Urban Green. 2013, 12, 163-170. [CrossRef]

36. Scopelliti, M.; Carrus, G.; Bonaiuto, M. Is it Really Nature That Restores People? A Comparison with Historical Sites with High Restorative Potential. Front. Psychol. 2019, 9, 1-12. [CrossRef]

37. Purcell, T.; Peron, E.; Berto, R. Why do Preferences Differ between Scene Types? Environ. Behav. 2001, 33, 93-106. [CrossRef]

38. Herzog, T.R.; Rector, A.E. Perceived danger and judged likelihood of restoration. Environ. Behav. 2009, 41, 387-401. [CrossRef]

39. Van den Berg, A.E.; Joye, Y.; Koole, S.L. Why viewing nature is more fascinating and restorative than viewing buildings: A closer look at perceived complexity. Urban For. Urban Green. 2016, 20, 397-401. [CrossRef]

40. Hartig, T.; Mang, M.; Evans, G. Restorative effect of natural experiences. Environ. Behav. 1991, $23,3-26$. [CrossRef]

41. Ohly, H.; White, M.P.; Wheeler, B.W.; Bethel, A.; Ukoumunne, O.C.; Nikolaou, V.; Garside, R. Attention Restoration Theory: A Systematic Review of the Attention Restoration Potential of Exposure to Natural Environments. J. Toxicol. Environ. Health Part B 2016, 19, 305-343. [CrossRef]

42. Ulrich, R.S.; Simons, R.F.; Losito, B.D.; Fiorito, E.; Miles, M.A.; Zelson, M. Stress recovery during exposure to natural and urban environments. J. Environ. Psychol. 1991, 11, 201-230. [CrossRef] 
43. Ulrich, R.S. Aesthetic and affective response to natural environment. In Human Behavior and Environment; Altman, I., Wohlwill, J., Eds.; Plenum: New York, NY, USA, 1983; Volume 6, pp. 85-125. [CrossRef]

44. Ward Thompson, C.; Roe, J.; Aspinall, P.; Mitchell, R.; Clow, A.; Miller, D. More green space is linked to less stress in deprived communities: Evidence from salivary cortisol patterns. Landsc. Urban Plan. 2012, 105, 221-229. [CrossRef]

45. Gatersleben, B.; Andrews, M. When walking in nature is not restorative-The role of prospect and refuge. Health Place 2013, 20, 91-101. [CrossRef] [PubMed]

46. Milligan, C.; Bingley, A. Restorative places or scary spaces? The impact of woodland on the mental well-being of young adults. Health Place 2007, 13, 799-811. [CrossRef] [PubMed]

47. Tuan, Y.F.F. Space and Place: The Perspective of Experience, 5th ed.; University of Minnesota Press: Minneapolis, UK, 2007. [CrossRef]

48. Bixler, R.D.; Carlisle, C.L.; Hammitt, W.E.; Floyd, M.F. Observed fears and discomforts among urban students on field trips to wildland areas. J. Environ. Educ. 1994, 26, 24-33. [CrossRef]

49. Bombieri, G.; Naves, J.; Penteriani, V.; Selva, N.; Fernández-Gil, A.; López-Bao, J.V.; Ambarli, H.; Bautista, C.; Bespalova, T.; Bobrov, V.; et al. Brown bear attacks on humans: A worldwide perspective. Sci. Rep. 2019, 9, 1-10. [CrossRef]

50. Moro, P.A.; Assisi, F.; Cassetti, F.; Bissoli, M.; Borghini, R.; Davanzo, F.; Della Puppa, T.; Dimasi, V.; Ferruzzi, M.; Giarratana, T.; et al. Toxicological hazards of natural environments: Clinical reports from Poison Control Centre of Milan. Urban For. Urban Green. 2009, 8, 179-186. [CrossRef]

51. Eder, M.; Cortes, F.; Teixeira de Siqueira Filha, N.; Araújo de França, G.V.; Degroote, S.; Braga, C.; Ridde, V.; Turchi Martelli, C.M. Scoping review on vector-borne diseases in urban areas: Transmission dynamics, vectorial capacity and co-infection. Infect. Dis. Poverty 2018, 7, 1-24. [CrossRef]

52. Kuo, F.E.; Sullivan, W.C. Environment and crime in the inner city does vegetation reduce crime? Environ. Behav. 2001, 33, 343-367. [CrossRef]

53. Van den Berg, A.; ter Heijne, M. Fear versus Fascination: An Exploration of Emotional Responses to Natural Threats. J. Environ. Psychol. 2005, 25, 261-272. [CrossRef]

54. Roe, J.J.; Aspinall, P.A.; Thompson, C.W. Coping with stress in deprived urban neighborhoods: What is the role of green space according to life stage? Front. Psychol. 2017, 8, 1-17. [CrossRef] [PubMed]

55. Neale, C.; Aspinall, P.; Roe, J.; Tilley, S.; Mavros, P.; Cinderby, S.; Coyne, R.; Thin, N.; Bennett, G.; Thompson, C.W. The Aging Urban Brain: Analyzing Outdoor Physical Activity Using the Emotiv Affectiv Suite in Older People. J. Urban Health 2017, 94, 869-880. [CrossRef] [PubMed]

56. Gardner, P.J. Natural neighborhood networks-Important social networks in the lives of older adults aging in place. J. Aging Stud. 2011, 25, 263-271. [CrossRef]

57. Dushkova, D.; Haase, D.; Haase, A. Urban green space in transition: Historical parks and soviet heritage in arkhangelsk, Russia. Crit. Hous. Anal. 2016, 3, 61-70. [CrossRef]

58. Tilley, S.; Neale, C.; Patuano, A.; Cinderby, S. Older people's experiences of mobility and mood in an urban environment: A mixed methods approach using electroencephalography (EEG) and interviews. Int. J. Environ. Res. Public Health 2017, 14, 151. [CrossRef]

59. Lev, E.; Kahn, P.H.J.; Chen, H.; Esperum, G. Relatively Wild Urban Parks Can Promote Human Resilience and Flourishing: A Case Study of Discovery Park, Seattle, Washington. Front. Sustain. Cities 2020, 2, 1-12. [CrossRef]

60. Hofmann, M.; Westermann, J.R.; Kowarik, I.; Meer, E.V.D.; Van der Meer, E. Perceptions of parks and urban derelict land by landscape planners and residents. Urban For. Urban Green. 2012, 11, 303-312. [CrossRef]

61. Lange, G.M.; Wodon, Q.; Carey, K. The Changing Wealth of Nations 2018: Building a Sustainable Future; World Bank Group: Washington, DC, USA, 2018. [CrossRef]

62. Beatley, T.; Newman, P. Biophilic cities are sustainable, resilient cities. Sustainability 2013, 5, 3328-3345. [CrossRef]

63. Thwaites, K.; Helleur, E.; Simkins, I.M. Restorative urban open space: Exploring the spatial configuration of human emotional fulfilment in urban open space. Landsc. Res. 2005, 30, 525-547. [CrossRef]

64. Ogden, N. Vector-Borne Disease, Climate Change and Urban Design; Canada Communicable Disease Report; Public Health Agency of Canada: Ottawa, ON, Canada, 2016; Volume 42, p. 202. [CrossRef] 
65. Mathieu, K.; Karmali, M. Vector-Borne Diseases, Climate Change and Healthy Urban Living: Next Steps; Canada Communicable Disease Report; Public Health Agency of Canada: Ottawa, ON, Canada, 2016; Volume 42, pp. 219-221. [CrossRef]

66. Martens, D.; Gutscher, H.; Bauer, N. Walking in "wild" and "tended" urban forests: The impact on psychological. J. Environ. Psychol. 2011, 31, 36-44. [CrossRef]

67. Chiang, Y.C.C.; Li, D.; Jane, H.A.A. Wild or tended nature? The effects of landscape location and vegetation density on physiological and psychological responses. Landsc. Urban Plan. 2017, 167, 72-83. [CrossRef]

68. Di Ieva, A. (Ed.) The Fractal Geometry of the Brain; Springer Series in Computational Neuroscience; Springer: New York, NY, USA, 2016. [CrossRef]

69. Carlson, A. On the aesthetic appreciation of Japanese gardens. Br. J. Aesthet. 1997, 37, 47-56. [CrossRef]

70. Tan, Z.; Lau, K.K.L.; Roberts, A.C.; Chao, S.T.Y.; Ng, E. Designing urban green spaces for older adults in asian cities. Int. J. Environ. Res. Public Health 2019, 16, 4423. [CrossRef]

71. Kendal, D.; Flies, E.; Marsh, P.; Jones, P.; Threlfall, C.; Egerer, M.; Jones, M.; Anders, R.; Collie, N.; Kaplan, H.; et al. Managing Urban Landscapes for Biodiversity Conservation and Human Health; Technical Report Report for the Healthy Landscapes Research Group; University of Tasmania: Hobart, Australia, 2019.

(C) 2020 by the author. Licensee MDPI, Basel, Switzerland. This article is an open access article distributed under the terms and conditions of the Creative Commons Attribution (CC BY) license (http:/ / creativecommons.org/licenses/by/4.0/). 